\title{
Proposing Certificate Plan for Controlling Electric Pollution on Cloud Data Storage Center
}

\author{
Rimmy Chuchra \\ Department of Computer \\ Science \& Engineering \\ Sri Sai College of Engg and Technology, \\ Mannawala(Amritsar)
}

\author{
R. K. Seth \\ Department of Physics \\ Dav University, Jalandhar
}

\begin{abstract}
The area of green computing has been emerged as an interesting field of research in this technology oriented world. Even small activities in daily life are dependent upon computer based technologies. This paper proposes a new methodology to provide Certificate Plan for Controlling Electric Pollution on Cloud Data Storage Centers with the purpose to control electric pollution and that provides a healthier and safer environment from different types of hazardous materials and other related computer electronics devices. The motivation towards this work is to improve our environmental conditions and reduce the effect of toxic electronics based materials. The function of new designed methodology actually analyze and measure the amount of carbon footprint by utilizing different instruments and methods that comes out from CRT'S (cathode ray tubes) and radiations emitted through other different parts of computer electronics in the form of hazardous gases $\left(\mathrm{No}_{2}, \mathrm{Co}_{2}\right)$ and hazard metals as like lead, cadmium and mercury. Authors are considering one more important parameter in this paper named as "load balancing". It describes if the government allotted space will be fulfilled in particular cloud data storage center (CDSC) then rather than implemented a new servers on that particular cloud data storage center that cloud storage agency may shift their data for storage in nearby any other cloud storage agency after analyzing the free space availability with the permission of government as well as that particular agency owner. This agreement must be signed legally by both the parties before the transfer of data.
\end{abstract}

\section{Keywords}

Cloud data storage center, green computing, e-transactions, Certificate plan, internet, and electric pollution, global warming (environment)

\section{INTRODUCTION}

In digital world, most of the tasks are computer dependent. Most of the users are performing their daily routine tasks through online-transactions as an example online ticket reservation, online training and online appointment etc. This greater dependency of tasks on computers is slowly-2 increases its demand in every field. For describing the more need of computers authors are considering the most common examples related to our daily life whose are based on internet services as like Watts app calling and Facebook calling is totally free for users that only require internet connection so people preferred more. The main reason to use such types of free internet services is to connect yourself with anywhere in the world and talk freely. Due to large advantages of such types of internet services in digital world as authors noticed, the range of personnel computers with internet connection is going to be too high day by day and even you see now a days in every home even a kid having age of 7 to 8 years is at first demanding for personnel computer for his or her fun like for playing as well as entertainment purpose. This increased demand of computers correspondingly increase electric pollution in our environment and converted into unhealthier environment that ultimately effects on human health as an example imbalanced greenhouse gases badly effect on human health. After the survey, authors noticed when computer machine is started by the user then different types of radiations and hazard gases like so2 and no2 [1] [6] are emitted from it and slowly-2 they started to pollute our environment [16] in the form of air pollution [1] [6]. This polluted environment further slowly-2 effects on human's health [11] for long run by spreading several types of diseases like damaged nervous system and damaged immune system etc. Such kind of diseases only due to usage of hazard gases as well as hazard material as like carbon di oxide, berillyium,lead metal, mercury metal, nitrogen di oxide and ICT (information and communication technology) [7] [9]. The list of different hazard material and hazard gases with examples of human health impacts can be shown in table 1 :

Table.1: Summary of hazard gases and heavy metals on human health [1][6].

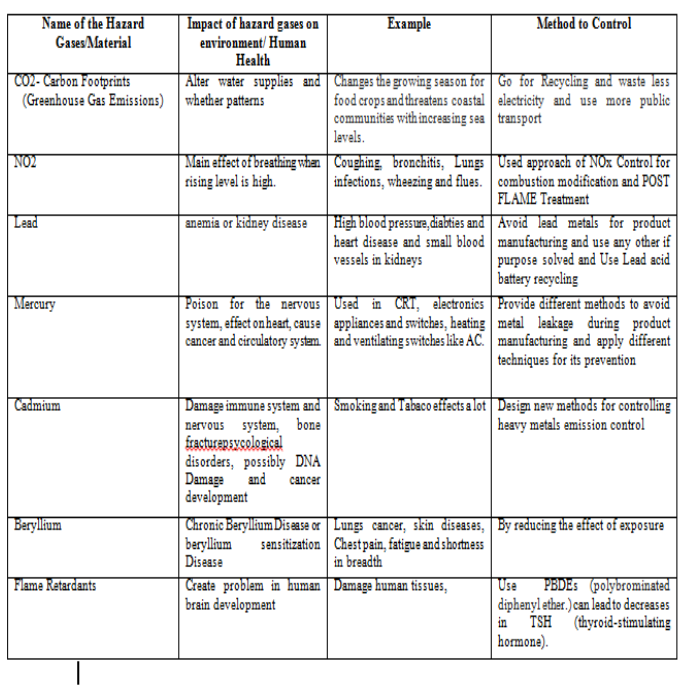

The maximum usage of above given toxic material as well as toxic gases actually spoil humans and our environment. After the completion of authors literature review, they noticed India and china both of two countries are the main hubs of e-waste [2] [4]. So, for reducing or controlling the amount of e-waste [2] [4] experts are demanding for designing new methodologies and strategies with required joint effort form both the ends viz. government end, professionals end and public end. This is right time for professionals to contribute in 
this scenario of save humans - save earth by designing new strategies and methods so that electric pollution will be controlled as soon as possible. And on another side they suggested to especially concentrate on the field of computer parts manufacturing companies and analysis the types of materials and metals used in? And also take care of the recyclability growth of that specific computer part. So that every parameter of each metal say its properties, merits and demerits are studied in detail before using in the product manufacturing. So, experts contributed their efforts with the collaboration of industry, government and Green environment group for minimize the growth of e-waste,e-scrap,e-junk,esuppliers and e-discards[8] in our society [2][4]. This problem of electric pollution will be easily controlled while doing work in the era of green computing. This era of green computing helps us to reduce an amount of electric pollution. As authors already discussed when you turn on computer then it emits several different types of radiations then directly or indirectly damages our environment. The most common CRT'S (cathode Ray Tube) [14] produced electronic waste is in the form of carbon footprint [22]. For reducing the effect of carbon footprint [22] in our environment experts suggested to need a lot of work on of green computing [12] [17] [20] [30] and correspondingly for maximizing energy efficiency [14] [30] needs design new methodologies at recyclability mode [14] and converted into a new shape rather than ewaste[2][12]. In this way, authors said the area of green computing [12][17][20][30]helps a lot for reducing electric pollution. This electric pollution controlled environment will definitely provide a safe or healthy environment from toxic and hazard materials [9] in future for better living. As authors just go through from the recent studies of the area of green computing as they noticed the code of computer hardware designers are to be getting changed now. They implemented the approach of LAME CODE [13] on the time of coding of computer hardware parts. The main significance to utilize this LAME CODE[13] is it produced very less amount of radiations rather than previous conventional approach and correspondingly apply different proposed energy saving techniques [15] on the time of computer usage. As an example put their laptop on sleep mode or hibernate mode when not in used mode just for power saving. Authors also suggested, try to prefer mostly purchasing energy star tag products [9] [21]. The main significance to prefer energy star products is the less consumption or almost negligible amount of hazard gases especially from the mercury metal [3] and lead metal [23] in the environment. While the utilization of energy star products correspondingly experts also looking for finding the alternatives of energy sources even they are now studying in detail about solar cells, solar photo voltaic cells and solar energy [10] etc. Some of the professionals till now uses different green computing policies [24][30], green approaches as an example Product longevity, power Management, Telecomm uniting, Software and deployment optimization, material recycling etc. Apart from all these, number of different green computing techniques are available in the market to manage power level as like OS level, Hardware and Firmware Level, Virtualization level and Data center Level [19] etc. The only purpose to utilize these several methods and strategies is to reduce power consumption [18] [25] especially in cloud storage data centers [27][29] level. As results found by authors they concluded presently, we all have need to control electric pollution at cloud storage data centers [27][29] because of now a days they are the large hubs of cloud data storage and consumes a lot of electricity as well as energy amount so researchers have need to calculate the exact amount of power and energy consumption in each cloud storage data center[27][29] individually with their actual capacity and need to search and implement new dynamic resource provisioning for reducing the amount of power as well as energy[28]. The additional benefit to utilize this idea is an ease to calculate individual cloud storage data center [27] [29] operational cost [28]. Recently cloud service providers implemented the concept of Citrix virtualization for calculating operational cost of each transaction in which applications are running on independent platform for server running applications as well as for desktop running applications. Operating System running applications are also help to run virtual applications especially on device hardwareenable IT organization to deliver on business mandates [26].

In this research paper, authors designed a new methodology of Certificate Plan for controlling Electric Pollution on Cloud Data Storage Centers (CDSC) whose main function is to reduce the electric pollution and provide a healthier or safer environment to humans for their better living. The benefit to utilize this new designed methodology is to reduce the amount of power as well as energy wastage at cloud storage data centers [27] [29]. Here, authors designed a new certificate government approved plan policy for controlling electric pollution. Number of different parameters is considered by the safety professionals for providing a safer or healthier environment for human's better living. The owner of any particular cloud storage data center [27][29] must be store some specific amount of data as assigned or according to approved government plan policy and if the load of data on specific cloud data storage center [27][29] will be greater then it will be easily migrated/ shifted into another one nearby located cloud storage data center as per new designed policy to nearby locally cloud storage data center[27][29] region. This agreement must be legally signed by the government as well as the owner of that particular cloud storage data center [27] [29]. Instead of implemented new servers on the required cloud data storage centers[27] [29] or consuming more power as well as energy simply load will be transferred/shifted and managed through the transference of data into another cloud data storage center[27][29]. Before launching this new designed proposed methodology just noted the protocols must be followed by both of the parties. That is a legally signed document must be shown before the data transfer / data migration form the one cloud data storage end to another one.

\section{RESEARCH DESIGN}

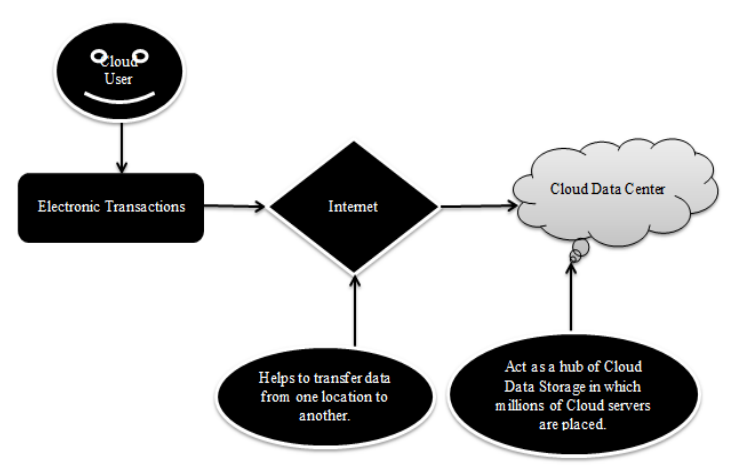

Fig.1: Interaction between Cloud User and Cloud Data Storage Center. 


\section{DESIGN OF ELECTRIC POLLUTION CONTROL CERTIFICATE (EPCC) FOR CLOUD DATA STORAGE CENTERS (CDSC)}

Design of Electric Pollution Control Certificate (EPCC) for Cloud Data Storage Centers (CDSC)

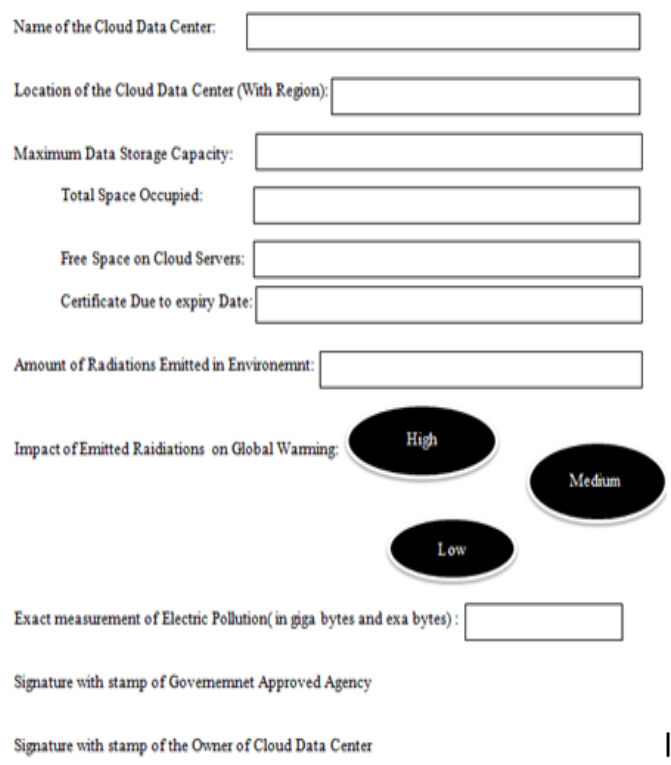

Figure 2: Proposed Design of EPCC

\section{CONCLUSIONS}

A variety of reasons causing electronic pollution are discussed in this paper such as e-waste and ICT (Information and Communication Technology) waste. The most of the people believe in replacement of e-material being used in computers rather than repairing approach. They simply burn the damaged electronic devices in an open environment resulting in air pollution. This paper also discussed about the harmful effects of dangerous gases/toxic gases on our health as shown in Table 1. The methodology is designed for Certificate Plan for Controlling Electric Pollution on Cloud Data Storage Centers) to minimize or control the electronic pollution successfully with the consent of government agency and that encourages the people to use or prefer energy star products. The benefit to utilize these energy star products in our daily life is to save energy, reducing emissions of $\mathrm{Co}_{2}$, air pollution and radiations. Utilizing, the concept of load balancing on particular cloud storage data center the greater amount of data will be easily shifted/transferred to the another cloud data storage center rather than implemented new servers on that specific cloud data storage center as per designed methodology. The implementation of the certificate will definitely provide a healthier and safer environment for our better living in future.

\section{FUTURE SCOPE}

The work may be extended by redesigning the different parts of our computer hardware components to reduce the power consumption for providing a healthier and safer environment for our future generations.

\section{REFERENCES}

[1] Jaggi bikki and Martin Freedman, 1991.Comparitive analysis of air pollution emissions by electric utilities: Public Policy Implications, Springer, Environment Management, NEW YORK.

[2] Kernal Sinha and Borthakur Anewesha, Electronic waste management in India”, Jawaharlal Nehru University, India, UCLA Library.

[3] Dr. Jinhuili and Dr. Shunichi Honda, 2008. Mercury in ewaste, Special feature: - E-Waste management.

[4] Masood Syed and Brooks Geoffrey, February 2014.Metal Extraction Processes for E-Waste and Existing Industrial Routes.

[5] Electric Vehicles Revisited: Costs, Subsidies and prospects, International Transport Forum, Paris, France April-2012.

[6] Aktsoglou.D and Angelakoglou.K, 2010. E-Waste: Environment problems and current management, Journal of engineering science and technology review.

[7] Krishna Ram, Study paper on e-waste management, TEC, New Delhi.

[8] Shah trupti and Bhai Vijay, February 2014. E-Waste: A New Environmental change, International journal of advanced research in computer science and software engg.

[9] Kaur Navdeep and Mittal Pardeep, March 2013.Green computing-Need and its implementation ,International journal of advanced research in computer engineering and technology.

[10] Sinha Kumar Anup and Garg I.K March 2014. Planning of designing a standalone solar power system for multibuilding organization, International journal of modern engg research.

[11] Gertsakis J and Horne ER, 2006. A Literature review on the environment and health impacts of waste electrical and electronic equipment, Report prepared for the ministry of Environment.

[12] Nalawade Ajay and Shinde Sharmila, July 2013. Green Computing: Go Green and Save Energy, International Journal of advanced research in computer science and software engg.

[13] Gupta Manisha and Jindal Gaurav, December 2012. Green Computing: Future of Computers, International journal of Engg research in management and technology.

[14] Sarvar Muhammad and Somro Rahim Tariq, Green Computing from current to future trends, College of engg and Technology, US.

[15] Software and Hardware: The future of green enterprise computing.

[16] Ganeshan.L, Uma Rani.C, MAY 2013.Green Computing:-Issues on the monitoring of personnel computers, International Journal of Engg and Science.

[17] Lanjewar A.U and A.Riyaz, November 2010.Green Computing-Embacce a Secure Future, International Journal of computer applications.

[18] Garg Arun and Kochhar, May 2011.Eco-Friendly Computing: Green Computing, International Journal of 
computing and business research.

[19] Chaudhary Sonu, 2014. A Survey on green computing techniques, International Journal of computer Science and information technology.

[20] Sarvar sood and gupta Apurav, February 2014.Green Computing: An approach of saving energy by computer virtualization, International Journal of application or innovation in engg and management.

[21] Kanu priya, December 2010.Green Computing saves green, International journal of advanced computer and mathematical sciences.

[22] Liu Yubao and Chen Chang, January 2013.Green databases through integration of renewable energy, $6^{\text {th }}$ Biennial conff. On innovative data systems research, California, US.

[23] Panda Ranjita, 2013.E-Waste management: A Step towards green computing, International Journal of Environment engg and management.

[24] Policies for green computing and e-waste the Romanian case, Academia Brancusi.
[25] Singhlal Deepali and Rekha, 2013.Challenges of the sustainable Green Computing, International journal of advance research in science and engg.

[26] Green IT: Reducing your carbon foot print with Citrix, White Paper.

[27] Patel Parveen and Maltz.A David, the cost of cloud: Research problems in data center networks, Microsoft Redmond, USA.

[28] Abawajy Jemal and Beloglazou Anton, Energy efficient management of data center resources for cloud computing: A Vision architectural elements \& open challenges, cloud computing \& distributed system lab, The University of Melbourne, Australia.

[29] Pietzuch peter and mallet barnabey, December 2010.Resource allocation across multiple cloud data centers, Banglore.

[30] Janmoni and singh kumar Sandeep, 2015. Power saving strategies in green cloud computing, International journal of grid distribution computing. 